\title{
Twilight observations suggest unknown sources of $\mathrm{HO}_{\mathbf{x}}$
}

\author{
P.O. Wennberg ${ }^{1}$, R.J. Salawitch ${ }^{2}$, D.J. Donaldson ${ }^{3}$, T.F. Hanisco ${ }^{4}$, E.J. \\ Lanzendorf $^{4}$, K.K. Perkins ${ }^{4}$, S.A. Lloyd ${ }^{5}$, V. Vaida ${ }^{6}$, R.S. Gao ${ }^{7}$, E.J. Hintsa ${ }^{4}$, \\ R.C. Cohen ${ }^{8}$, W.H. Swartz ${ }^{5}$, T.L. Kusterer ${ }^{5}$, D.E. Anderson ${ }^{5}$.
}

\begin{abstract}
Measurements of the concentrations of $\mathrm{OH}$ and $\mathrm{HO}_{2}\left(\mathrm{HO}_{\mathrm{x}}\right)$ in the high-latitude lower stratosphere imply the existence of unknown photolytic sources of $\mathrm{HO}_{\mathrm{x}}$. The strength of the additional $\mathrm{HO}_{\mathrm{x}}$ source required to match the observations depends only weakly on solar zenith angle (SZA) for $80^{\circ}<\mathrm{SZA}<93^{\circ}$. The wavelengths responsible for producing this $\mathrm{HO}_{\mathrm{x}}$ must be longer than $650 \mathrm{~nm}$ because the flux at shorter wavelengths is significantly attenuated at high SZA by scattering and absorption. Provided that the sources involve only a single photon, the strength of the bonds being broken must be $<45 \mathrm{kcal}^{\text {mole }}{ }^{-1}$. We speculate that peroxynitric acid $\left(\mathrm{HNO}_{4}\right)$ dissociates after excitation to an unknown excited state with an integrated band cross section of $2-3 \times 10^{-20} \mathrm{~cm}^{2}$ molecule ${ }^{-1} \mathrm{~nm}(650<\lambda<1250 \mathrm{~nm})$.
\end{abstract}

\section{Introduction}

Measurement of the SZA dependence of short-lived radical species such as $\mathrm{OH}$ and $\mathrm{HO}_{2}$ provides insight into their sources [e.g. Salawitch et al., 1994]. In this letter we report twilight observations from a NASA ER-2 aircraft obtained near Fairbanks, Alaska during the 1997 Photochemistry of Ozone Loss in the Arctic Region In Summer (POLARIS) campaign. Observations at high latitudes are exceptionally well suited to this analysis: because of the slowly varying $\mathrm{SZA},\left[\mathrm{HO}_{\mathrm{x}}\right]$ remains near instantaneous steady state $\left(\mathbf{P}_{\mathrm{HOx}} \approx\right.$ $\mathrm{L}_{\mathrm{HO}}$ 》 $\mathrm{d}\left[\mathrm{HO}_{\mathrm{x}}\right] / \mathrm{dt}$ ) at SZA as large as $93^{\circ}$.

Previously, high-SZA measurements of $\mathrm{HO}_{\mathrm{x}}$ were made during the 1993 Stratospheric Photochemistry, Aerosols, and Dynamics Expedition (SPADE). These observations showed that $\left[\mathrm{HO}_{\mathrm{x}}\right]$ was higher than expected and implied the existence of unknown sources of these radicals present throughout the day. Most pronounced was the rapid onset of $\left[\mathrm{HO}_{\mathrm{x}}\right]$ in the early morning - consistent with nighttime production of a photo-labile hydroxyl-containing species. Some of us speculated that $\mathrm{HNO}_{4}$ might be hydrolyzed on sulfate aerosols producing HONO [Salawitch et al., 1994]. Subsequent studies showed, however, that such hydrolysis does not occur [Zhang et al., 1997]. After the SPADE observations, Hanson and Ravishankara [1995] discovered that $\mathrm{BrONO}_{2}$ was hydrolyzed to $\mathrm{HOBr}$ in sulfuric acid. This production of $\mathrm{HOBr}$

\footnotetext{
TCalifornia Institute of Technology, Pasadena.

${ }^{2}$ Jet Propulsion Laboratory, California Inst. of Tech., Pasadena.

${ }^{3}$ Department of Chemistry, University of Toronto, Canada.

${ }^{4}$ Department of Chemistry, Harvard University, Cambridge, MA.

${ }^{5}$ Applied Physics Lab., Johns Hopkins Univ., Laurel, MD.

${ }^{6}$ Department of Chemistry, University of Colorado, Boulder.

${ }^{7}$ NOAA Aeronomy Laboratory, Boulder, CO.

${ }^{8}$ Department of Chemistry, University of California, Berkeley.
}

Copyright 1999 by the American Geophysical Union.

Paper number 1999GL900255.

0094-8276/99/1999GL900255\$05.00 together with the recently discovered transition to a low-lying triplet state of $\mathrm{HOBr}$ centered near $500 \mathrm{~nm}$ [Barnes et al., 1996] leads to significant production of $\mathrm{HO}_{\mathrm{x}}$ at sunrise in model calculations [e.g., Lary et al., 1996].

Recent studies have pointed to other processes that produce $\mathrm{HO}_{\mathrm{x}}$ near twilight. Studies of the photolysis of $\mathrm{O}_{3}$ have shown that $O\left({ }^{1} D\right)$ is produced in a spin-forbidden process at wavelengths as long as $411 \mathrm{~nm}$, significantly increasing the production rate of $\left.\mathrm{O}^{1} \mathrm{D}\right)$ for $\mathrm{SZA}>85^{\circ}$ [Ravishankara et al., 1998 and references therein]. Recently, Donaldson et al. [1997] have suggested that excitation of vibrational overtones of the $\mathrm{OH}$ stretch in $\mathrm{HNO}_{3}$ and $\mathrm{HNO}_{4}$ may provide a significant source of $\mathrm{HO}_{\mathrm{x}}$ at high SZA.

\section{HO $_{\mathrm{x}}$ at High SZA During POLARIS}

The high-latitude, high-SZA observations obtained during POLARIS are distinct from those of SPADE and provide a different test of $\mathrm{HO}_{\mathrm{x}}$ photochemistry. Nighttime is shorter; the lower stratosphere is warmer ( 228 vs. $212 \mathrm{~K}$ ); total reactive nitrogen $\left(\mathrm{NO}_{\mathrm{y}}\right)$ is a factor of two higher; and $\left[\mathrm{NO}_{2}\right]$ is nearly five times larger. In the intervening four years, aerosol surface area has declined by more than a factor of five.

In this study we compute the diurnal variation of $[\mathrm{OH}]$ and $\left[\mathrm{HO}_{2}\right]$ using a model constrained with measured values of pressure, temperature, aerosol surface area, and the concentrations of radical precursors (e.g. $\mathrm{O}_{3}, \mathrm{H}_{2} \mathrm{O}$, and $\left.\mathrm{CH}_{4}\right)($ Table 1). Inorganic bromine, $\mathrm{Br}_{\mathrm{y}}$, and chlorine, $\mathrm{Cl}_{\mathrm{y}}$, are inferred from measurements of their source gases made by the whole air sampler and the airborne gas chromatograph. The $\mathrm{O}_{3}$ column and its altitude distribution are inferred from Total Ozone Mapping Spectrometer (TOMS) data and from $\mathrm{O}_{3}$ measurements obtained on the ER-2 and balloon-borne sondes. At SZA $<85^{\circ}$, this technique agrees with overhead $\mathrm{O}_{3}$ measured by the ER-2 UV/Vis spectrometer. For $\mathrm{SZA}>85^{\circ}$, however, the overhead $\mathrm{O}_{3}$ column inferred from the spectrometer is not considered reliable [C.T. McElroy, personal communication]. TOMS reflectivity measurements are used to constrain the albedo along the flight track.

Interpretation of the $\mathrm{HO}_{\mathrm{x}}$ observations requires correct representation of $\mathrm{NO}_{\mathrm{x}}$ in the model because numerous processes couple these radicals. For most of the POLARIS, observations of [NO] and $\left[\mathrm{NO}_{2}\right]$ are $20-40 \%$ larger than calculated using rate coefficients from DeMore et al. [1997] (Gao et al. [1999]; Osterman et al. [1999]). To assure calculated $\mathrm{NO}_{\mathrm{x}}$ at twilight matches observation, we use recently reported rate coefficients for the reactions of $\mathrm{OH}$ with $\mathrm{HNO}_{3}$ and $\mathrm{NO}_{2}$ [Brown et al., 1999; Dransfield et al., 1999] and account for the remaining model-measurement disagreement $(<10 \%)$ by relaxing the requirement that the partitioning between $\mathrm{NO}_{\mathrm{x}}$ and $\mathrm{NO}_{\mathrm{y}}$ be in steady-state.

Figure 1 shows the measured $\left[\mathrm{HO}_{2}\right]$ on 30 April and 9 May 1997. For these flights, the pilot flew a 'race-track' pattern 


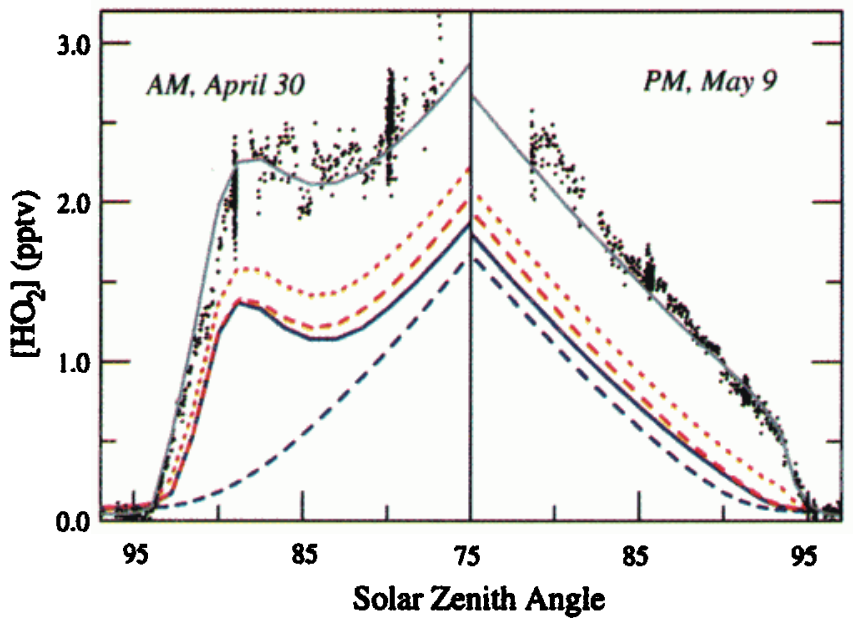

Figure 1. Measurements and model calculations for $\left[\mathrm{HO}_{2}\right]$ on 30 April 1997 and 9 May 1997. All calculations use recently reported rate coefficients for the reactions of $\mathrm{OH}$ with $\mathrm{NO}_{2}$ and $\mathrm{HNO}_{3}$. The solid blue line depicts a calculation using rate coefficients and cross sections from DeMore et al. [1997] for all other processes (JPL97*). The blue dashed line shows the same calculation without allowing for the hydrolysis of $\mathrm{BrONO}_{2}$. The red dashed line is JPL97* with the addition of the spin-forbidden production of $\left.O{ }^{1} D\right)$ in the near UV. The red dotted line displays a calculation that adds, in addition, production of $\mathrm{HO}_{\mathbf{x}}$ from the excitation of overtones of the OH stretch in $\mathrm{HNO}_{3}$ and $\mathrm{HNO}_{4}$. The gray solid line is a model that includes an additional photolytic pathway for $\mathrm{HNO}_{4}$ placed at $800 \mathrm{~nm}$ (see text for details).

for nearly seven hours. Minimal variation $( \pm 15 \%)$ in the mixing ratio of long-lived tracers such as $\mathrm{O}_{3}, \mathrm{CH}_{4}, \mathrm{~N}_{2} \mathrm{O}$, and $\mathrm{NO}_{y}$ was observed at $75^{\circ}<\mathrm{SZA}<97^{\circ}$. The solid blue line displays a calculation using, with the exception of the reactions noted above, rate coefficients and absorption cross sections from DeMore et al. [1997]. The observed $\left[\mathrm{HO}_{2}\right]$ is larger than calculated by essentially a constant 0.75 pptv.

Potential systematic errors in the $\mathrm{HO}_{x}$ observations may be as large as $30 \%$ with an additional zero offset of $\pm \mathbf{0 . 0 5}$ pptv. The precision of the calibration of the instrument, however, is much better: any systematic error will not change significantly from flight to flight or vary with SZA. This precision is critical to this analysis; although differences between the observations and calculated $\left[\mathrm{HO}_{\mathrm{x}}\right]$ at low SZA are not significant, the fractional variation of the difference with SZA is significant. At $92^{\circ} \mathrm{SZA}$, this difference is greater than $60 \%$. The comparison for $\mathrm{OH}$ is essentially the same, though the signalto-noise ratio of the $\mathrm{OH}$ observations is lower because its concentration is ten to fifteen times smaller.

Errors in the representation of bromine chemistry cannot account for all the differences shown in Figure 1. The heterogeneous reaction of $\mathrm{BrONO}_{2}$ with $\mathrm{H}_{2} \mathrm{O}$ is calculated to convert more than $60 \%$ of the $\mathrm{Br}_{\mathrm{y}}$ to $\mathrm{HOBr}$ over night, leading to a rapid increase in calculated $\left[\mathrm{HO}_{\mathrm{x}}\right]$ in the early moming. The blue dashed line (Figure 1) shows a calculation without this hydrolysis reaction. We use a reaction probability $(\gamma)$ of 0.8 . By assuming $\gamma=1$ and increasing our estimate for $\mathrm{Br}_{y}$ by $-30 \%$, the agreement with measured $\left[\mathrm{HO}_{2}\right]$ at sunrise is significantly improved. These changes however, do not improve agreement at sunset. Furthermore, recent laboratory data sug-

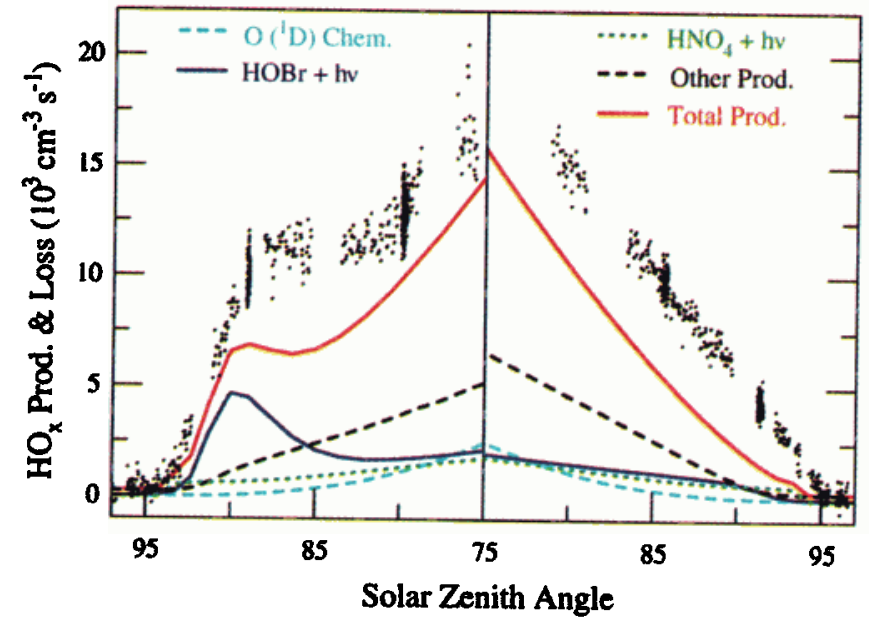

Figure 2. Production and loss rate of $\mathrm{HO}_{\mathrm{x}}$. In the full model (dotted red Figure 1), $\mathrm{HO}_{x}$ production from $\mathrm{O}\left({ }^{1} \mathrm{D}\right)$ chemistry is important only at the lowest SZA. At high SZA, production is dominated by photolysis of $\mathrm{HO}_{\mathrm{x}}$ reservoirs such as $\mathrm{HNO}_{3}, \mathrm{HNO}_{4}$, and $\mathrm{HOBr}$. Photolysis of $\mathrm{HOCl}$ and methane oxidation make up most of the undifferentiated sources. The $\mathrm{HO}_{\mathbf{x}}$ loss rate (data points) is determined from the measured abundances of $\mathrm{HO}_{\mathbf{x}}, \mathrm{NO}_{x}$, and $\mathrm{NO}_{y}\left(\left[\mathrm{HNO}_{3}\right]\right.$ is estimated by $\left[\mathrm{NO}_{y}\right]-\left[\mathrm{NO}_{x}\right]-\left[\mathrm{ClNO}_{3}\right]-2 \times\left[\mathrm{N}_{2} \mathrm{O}_{5}\right]$, where $\left[\mathrm{N}_{2} \mathrm{O}_{5}\right]$ is estimated from measured $\mathrm{NO}_{\mathrm{x}}$ ). The $\mathrm{HO}_{\mathrm{x}}$ sink exceeds the calculated source by nearly a constant amount for $\mathrm{SZA} \leq 93^{\circ}$.

gest that $\gamma$ is likely $2-4$ times smaller at $T=230 \mathrm{~K}$ [D. Hanson, personal communication].

Including the spin-forbidden production of $O\left({ }^{1} D\right)$ in the photolysis of $\mathrm{O}_{3}$ (Figure 1) has a negligible effect on $\left[\mathrm{HO}_{x}\right]$ at high SZA because production of $\mathrm{HO}_{\mathrm{x}}$ is dominated by processes involving reservoir species such as $\mathrm{HNO}_{3}, \mathrm{HNO}_{4}$, and

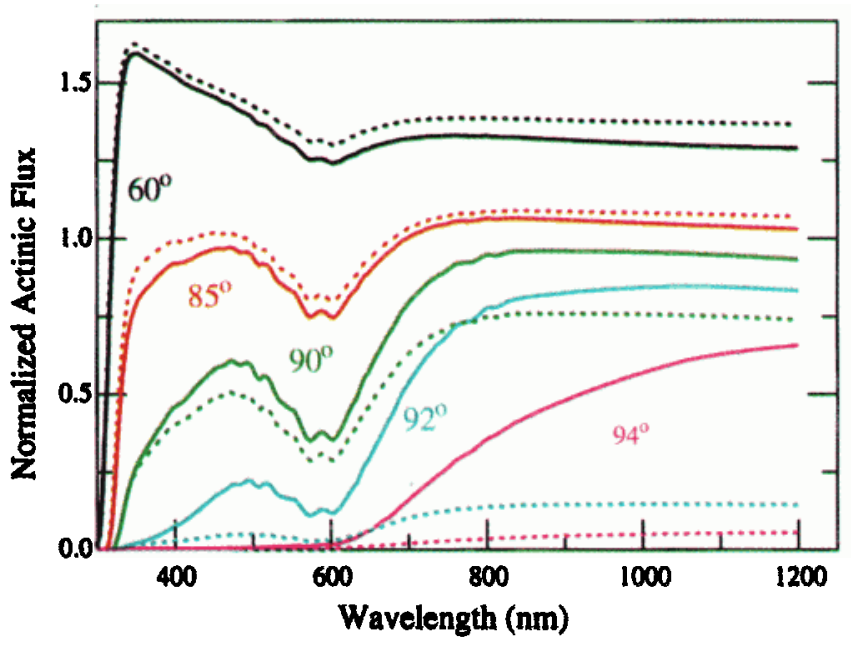

Figure 3. The local actinic flux at $20 \mathrm{~km}$ divided by the flux at the top of the atmosphere $\left(\mathrm{F}_{\mathrm{o}}\right)$ depends strongly on SZA for wavelengths $<650 \mathrm{~nm}$ in the POLARIS atmosphere (solid lines). With heavy aerosol loading during the 1993 SPADE campaign (defined in Salawitch et al. [1994]), $\mathrm{F} / \mathrm{F}_{\mathrm{o}}$ (dashed lines) was much lower at high SZA. Aerosol optical depth is determined from remote observations by the SAGE II instrument. 
Table 1. Model Constraints

\begin{tabular}{lll}
\hline & 30 April 1997 & 9 May 1997 \\
\hline Temperature & $228 \mathrm{~K}$ & $228 \mathrm{~K}$ \\
Pressure & $66.0 \mathrm{mb}$ & $62.5 \mathrm{mb}$ \\
Latitude & $64.0^{\circ} \mathrm{N}$ & $64.3^{\circ} \mathrm{N}$ \\
$\mathrm{H}_{2} \mathrm{O} / \mathrm{CH} \mathrm{H}_{4}$ & $4.8 / 1.3 \mathrm{ppmv}$ & $4.8 / 1.3 \mathrm{ppmv}$ \\
$\mathrm{O}_{3}$ & $2.4 \mathrm{ppmv}$ & $2.6 \mathrm{ppmv}$ \\
$\mathrm{CO}$ & $12.5 \mathrm{ppbv}$ & $12.5 \mathrm{ppbv}$ \\
$\mathrm{NO}_{\mathrm{y}}$ & $7.5 \mathrm{ppbv}$ & $7.5 \mathrm{ppbv}$ \\
$\mathrm{Br}_{\mathrm{y}} / \mathrm{Cl}$ & $12.9 / 1780 \mathrm{pptv}$ & $12.9 / 1780 \mathrm{pptv}$ \\
$\mathrm{NO}_{\mathrm{x}}$ at solar noon & $1.0 \mathrm{ppbv}$ & $1.05 \mathrm{ppbv}$ \\
$\mathrm{O}_{3}$ column (above ER-2) & $203 \mathrm{DU}$ & $201 \mathrm{DU}$ \\
$\mathrm{O}_{3}$ column (Total) & $380 \mathrm{DU}$ & $390 \mathrm{DU}$ \\
$\mathrm{Albedo}$ & 0.25 & 0.10 \\
$\mathrm{Aerosol} \mathrm{surface} \mathrm{area}^{2}$ & $1 \mu \mathrm{mm}^{-3}$ & $1 \mu \mathrm{m}^{2} \mathrm{~cm}^{-3}$ \\
\hline
\end{tabular}

HOBr rather than by $O\left({ }^{1} D\right)$ chemistry (Figure 2). For example, the minor $\mathrm{HO}_{\mathrm{x}}$ source from thermal decomposition of $\mathrm{HNO}_{4}$ is calculated to exceed production from $O\left({ }^{\mathrm{l}} \mathrm{D}\right)$ chemistry by a factor of five at $\mathrm{SZA}=90^{\circ}$, even when the spin forbidden process is included. We have assumed an $O\left({ }^{i} D\right)$ quantum yield of 0.06 for $329<\lambda<411 \mathrm{~nm}$.

The red dotted line in Figure 1 displays a calculation that includes the dissociation of $\mathrm{HNO}_{3}$ and $\mathrm{HNO}_{4}$ by photoexcitation of overtones of the $\mathrm{OH}$ vibrational stretch. The $\mathrm{HNO}_{3}$ overtone intensities used here are from Donaldson et al. [1998]. Excitation of the $\mathrm{OH}$ stretch $\left(v_{1}\right)$ in $\mathrm{HNO}_{3}$ to $5 v_{1}$ (5 quanta) is partially dissociative and we use the quantum yield from Donaldson et al. [1997]. Only 3 quanta of excitation of the $\mathrm{OH}$ stretch are required to exceed the $\mathrm{N}-\mathrm{OOH}$ bond strength in $\mathrm{HNO}_{4}\left(\mathrm{D}_{\mathrm{o}}=22.8 \mathrm{kcal} \mathrm{mole}{ }^{-1}\right.$ [Zabel, 1995]). The gas-phase cross sections for this transition are unknown. We use measurements of the $\mathrm{HNO}_{4}$ cross sections obtained in a solution of concentrated $\mathrm{H}_{2} \mathrm{SO}_{4}$ prepared by reacting $\mathrm{NaNO}_{2}$ with $\mathrm{H}_{2} \mathrm{O}_{2}$ (a modification of the procedure of Appelman and Gosztola [1995]) [Donaldson et al., in preparation]. The integrated intensity of $3 v_{1}$ for $\mathrm{HNO}_{4}$ was $1.3 \pm 0.5$ times $3 v_{1}$ for $\mathrm{HNO}_{3}$ determined in the same fashion. We assume that the gas phase intensities scale similarly. Note that the $\mathrm{HO}_{\mathrm{x}}$ observations cannot be used to distinguish between sources of $\mathrm{OH}$ and $\mathrm{HO}_{2}$ because these species are interconverted on a time scale of less than $1 \mathrm{~min}$. The increase in calculated $\left[\mathrm{HO}_{2}\right]$ between the red dashed and dotted lines is entirely due to the different photolysis rate of $\mathrm{HNO}_{4}$. Although included, the increase in the photolysis rate of $\mathrm{HNO}_{3}$ neither significantly enhances $\left[\mathrm{HO}_{\mathrm{x}}\right]$ nor alters the partitioning of $\mathrm{NO}_{\mathrm{y}}$.

Figure 2 illustrates the diurnal dependence of $\mathrm{HO}_{\mathrm{x}}$ sources in the full model and the strength of the $\mathrm{HO}_{\mathrm{x}}$ sink determined from the atmospheric observations and the relevant rate coefficients. The calculated source and sink differ by essentially a constant amount for SZA $\leq 93^{\circ}$ and therefore the 'missing' source strength depends only weakly on SZA during daylight. The imbalance between production and loss of $\mathrm{HO}_{\mathrm{x}}$ cannot be attributed to an excess sink because the observations imply that the imbalance is independent of $\left[\mathrm{HO}_{\mathbf{x}}\right]$.

In Figure 3, the calculated actinic flux normalized to the flux incident on the Earth's atmosphere $\left(F / F_{0}\right)$ is shown as both a function of SZA and wavelength. Two radiative transfer programs were examined for this study [Salawitch et al., 1994; Anderson et al., 1995] and produce essentially identical results provided that the same ozone profiles are used (differ- ences $<10 \%$, for $F / F_{0}>1 \times 10^{-8}$ ). For $S Z A \geq 92^{\circ}$, significant values of $F / F_{o}$ occur only for wavelengths $>650 \mathrm{~nm}$ (the end of the $\mathrm{O}_{3}$ Chappius band). Comparison of the SZA dependence of the missing source and radiation field suggests that the photolysis must occur in the red / near-IR region of the spectrum. The calculations shown in Figure 3 include the effects of refraction and aerosol scattering, but do not include the narrow absorption features in the visible / near IR due to $\mathrm{O}_{2}, \mathrm{H}_{2} \mathrm{O}$, and $\mathrm{O}_{2}$ collision pairs. For the aerosol loading characteristic of the POLARIS atmosphere, the effects of aerosol scattering and refraction are equal but of opposite sign. Uncertainty in the radiation field for SZA $>93^{\circ}$ is large due to clouds. We have assumed (based on TOMS climatology) that clouds are present at $500 \mathrm{mb}$. Such clouds advance sunset and delay sunrise by nearly $1^{\circ}$.

Could excited-state $\mathrm{O}_{2}$ chemistry be the missing source? Toumi [1993] has suggested that $\mathrm{O}_{2}\left(b^{1} \Sigma_{\mathrm{g}}\right)+\mathrm{H}_{2}$ would be an important $\mathrm{HO}_{\mathrm{x}}$ source even if only a small fraction of the total rate of this reaction produced $\mathrm{OH}$. Even though $\mathrm{O}_{2}\left(b^{1} \Sigma_{\mathrm{g}}\right)$ is produced in the near $\mathbb{R}$, this process cannot be responsible for the $\mathrm{HO}_{\mathrm{x}}$ production at high SZA because the large optical depth at the $\mathrm{O}_{2} \mathrm{~A}, \mathrm{~B}$, and $\gamma$ bands leads to a strong SZA dependence for the production rate of $\mathrm{O}_{2}\left(b^{1} \Sigma_{\mathrm{g}}\right)$. $\left(\mathrm{P}_{\mathrm{SZA}=75}>10 \times\right.$ $\mathbf{P}_{\mathrm{SZA}}=$ 92, [M. Mlynczak and B.T. Marshall, pers. comm.]). For the conditions described in Table 1 this source cannot be important at twilight and would only be important for midday [HO $]$ if the quantum yield for $\mathrm{HO}_{\mathrm{x}}$ production is $\sim 200 \%$.

In contrast to the observations obtained during POLARIS, the 1993 SPADE measurements do not suggest significant production of $\mathrm{HO}_{\mathrm{x}}$ at $\mathrm{SZA}>90^{\circ}$ [Salawitch et al., 1994]. We find that the diurnal dependence of $\left[\mathrm{HO}_{\mathrm{x}}\right]$ measured during SPADE is, within the uncertainty of the measurements, adequately described by the full model (e.g. red dotted model, Figure 1). However, the SPADE observations are not inconsistent with the POLARIS measurements because in 1993 the stratospheric aerosol loading was sufficiently high that aerosol scattering significantly darkened the sky at $\mathrm{SZA} \geq 91^{\circ}$ throughout the visible / near IR (Figure 3).

\section{Missing photochemistry of $\mathrm{HNO}_{4}$ ?}

The requirement that the missing $\mathrm{HO}_{\mathrm{x}}$ sources be produced by solar radiation at $\lambda>650 \mathrm{~nm}$ places a significant constraint on the energetics of these processes. The thermodynamic limits for the production of $\mathrm{HO}_{\mathrm{x}}$ from $\mathrm{HOCl}, \mathrm{H}_{2} \mathrm{O}_{2}, \mathrm{HONO}$, $\mathrm{HOBr}, \mathrm{HNO}_{3}$, and $\mathrm{HNO}_{4}$ are $518,557,572,591,598$, and $1250 \mathrm{~nm}$, respectively. Thus, $\mathrm{HNO}_{4}$ is one of the few $\mathrm{HO}_{\mathrm{x}}$ reservoir species that has a sufficiently weak bound to allow photodissociation with single photons of these energies (650 $\mathrm{nm}$ photons have an energy of $44 \mathrm{kcal} \mathrm{mole}^{-1}$ ).

As illustrated in Figure 1, the $\mathrm{HO}_{\bar{x}}$ chemistry at high SZA can be balanced by the addition of a photolytic pathway for $\mathrm{HNO}_{4}$ with a photolysis rate coefficient of $1 \times 10^{-5} \mathrm{~s}^{-1}$ (at F/Fo $=1$ ) arbitrarily placed at $800 \mathrm{~nm}$. Including this process in the model increases the 24 hour average $\left[\mathrm{HO}_{\mathrm{x}}\right]$ by $\sim 20-30 \%$ in these airmasses and improves the agreement between measured and calculated $\mathrm{HO}_{\mathrm{x}}$ for all POLARIS flights. This process would also resolves the model-measurement discrepancies for $\left[\mathrm{HNO}_{4}\right]$ obtained by the MkIV balloon-borne interferometer during POLARIS [Salawitch et al., in prep.]. With this process included, the calculated $\left[\mathrm{HNO}_{4}\right]$ drops by a factor of $\sim 2$, reconciling the calculations with observations. 
This result is largely insensitive to assumptions about the UV cross sections of $\mathrm{HNO}_{4}$. The two studies used in the JPL evaluation differ significantly at $\lambda>310 \mathrm{~nm}$ [Molina and Molina, 1981; Singer et al., 1989] and the DeMore et al. [1997] recommendation does not extend beyond $325 \mathrm{~nm}$. We have assumed that the UV cross section for $\mathrm{HNO}_{4}$ are 0 for $\lambda$ $>325 \mathrm{~nm}$. We have performed sensitivity studies to this assumption and find that our conclusion about the need for an additional $\mathrm{HO}_{\mathrm{x}}$ source longward of $650 \mathrm{~nm}$ is not changed. Although larger UV cross sections for $\mathrm{HNO}_{4}$ improve the agreement for $\left[\mathrm{HO}_{\mathrm{x}}\right]$ at low $\mathrm{SZA}$, the agreement at $\mathrm{SZA}>90^{\circ}$ is not sensitive to these cross sections because the actinic flux at $\lambda<400 \mathrm{~nm}$ is negligible at these SZA. The same is true for uncertainty in the ozone profile; a smaller ozone column above the ER-2 improves agreement at low SZA but does not change the model result at high SZA.

What spectroscopic transition could produce this photolysis? The $3 \mathrm{v}_{1}$ overtone of $\mathrm{HNO}_{4}$ is five times too weak. It is possible that combination bands of $2 v_{1}$ may be involved. These transitions have not been observed, however, and the thermochemistry of $\mathrm{HNO}_{4}$ is sufficiently uncertain that it is unclear whether excitation of these modes would be dissociative. Perhaps a singlet-triplet transition exists in $\mathrm{HNO}_{4}$ as has been shown to occur in HOBr [Barnes et al., 1996]. Photolysis of $\mathrm{HNO}_{4}$ in a transparent region of the red / near- $\mathbb{R}$ with an integrated band cross section of only $2.5 \times 10^{-20} \mathrm{~cm}^{2}$ molecule $^{-1} \mathrm{~nm}$ matches the required source of $\mathrm{HO}_{\mathrm{x}}$ (Figure 1). This increased photolysis rate would reduce the calculated importance of $\mathrm{HNO}_{4}$ both as a $\mathrm{NO}_{x}$ reservoir and a $\mathrm{HO}_{\mathrm{x}}$ sink. Work is underway at Caltech to study the photodissociation of $\mathrm{HNO}_{4}$ in the red/ near-IR.

\section{Conclusion}

High-SZA observations of $\mathrm{HO}_{\mathrm{x}}$ have demonstrated that a source of $\mathrm{HO}_{\mathrm{x}} \approx 3 \times 10^{3}$ molecules $\mathrm{cm}^{-3} \mathrm{~s}^{-1}$ persisting to very high SZA is missing from the photochemical description of the stratosphere. The source likely involves photolysis in the red or near IR because the optical depth of the atmosphere at shorter wavelengths is large at high SZA. Until the source molecules are identified, however, we cannot determine the extent to which these processes are important globally.

Acknowledgements. We thank NASA's Upper Atmosphere Research and the Atmospheric Effects of Aviation Programs for supporting the POLARIS field campaign (M. Kurylo, P. DeCola, and R. Kawa, project managers). POW acknowledges additional support from the NSF (ACM-9612282) for this work. DJD acknowledges NSERC for partial support of this work. VV acknowledges NSF for support. We thank $\mathrm{C}$. Webster (for $\mathrm{CH}_{4}$ and $\mathrm{CO}$ ), R. May (for $\mathrm{H}_{2} \mathrm{O}$ ), J. Margitan and M. Proffitt (for $\mathrm{O}_{3}$ ), C. Wilson and C. Brock (for aerosol surface area), J. Elkins and E. Atlas (for organic halogens), L. Thomason (for aerosol extinction), $\mathrm{R}$. McPeters $\left(\mathrm{O}_{3}\right.$ column and reflectivity), and M. Mlynczak and B.T. Marshall (for $\mathrm{O}_{2}\left(b^{1} \Sigma_{\mathrm{g}}\right)$ ). We appreciate the leadership of D. Fahey and P. Newman, POLARIS lead scientists. We thank A. Tuck for motivating this study. A portion of this work was performed at JPL under contract from NASA.

\section{References}

Appelman, E.H. and D.J. Gosztola, Aqueous peroxynitric acid $\left(\mathrm{HOONO}_{2}\right)$ - A novel synthesis and some chemical and spectroscopic properties, Inorg. Chem., 34, 787-791, 1995.

Anderson, D.E., et al., Impact of aerosols and clouds on the troposphere and stratosphere radiation-field with application to twilight at $20 \mathrm{~km}$. J. Geophys. Res., 100, 7135-7145, 1995.

Barnes, R.J., et al., Observation of a new absorption band of $\mathrm{HOBr}$ and its atmos. implications, J. Phys. Chem., 100, 453-457, 1996.

Brown, S.S., et al., Reconsideration of the rate constant for the reaction of $\mathrm{OH}$ with $\mathrm{HNO}_{3}$, J. Phys. Chem, in press, 1999.

Donaldson, D.J., et al., Atmospheric radical production by excitation of vibrational overtones via absorption of visible light, Geophys. Res. Lett., 24, 2651-2654, 1997.

Donaldson, D.J., et al., Absolute intensities of nitric acid overtones, J. Phys. Chem. A, 102, 5171-5174,1998.

Dransfield, T.J., et al., Temperature and pressure dependent kinetics of $\mathrm{OH}$ with $\mathrm{NO}_{2}$, Geophys. Res. Lett., 26, 687-690, 1999.

Gao, R.S. et al., A comparison of observations and model simulations of the $\mathrm{NO}_{\mathrm{x}} / \mathrm{NO}_{\mathrm{y}}$ ratio in the lower stratosphere, Geophys. Res. Lett., 26, 1153-1156, 1999.

Hanson, D.R., Ravishankara, A.R. Heterogeneous chemistry of bromine species in $\mathrm{H}_{2} \mathrm{SO}_{4}$, Geophys. Res. Lett, 22, 385-388, 1995.

Lary, D.J., et al., Heterogeneous atmospheric bromine chemistry, $J$. Geophys. Res., 101, 1489-1504, 1996.

Molina, M.J. and L.T. Molina, UV absorption cross sections of $\mathrm{HO}_{2} \mathrm{NO}_{2}$ vapor, J. Photochem., 15, 97-108, 1981.

Osterman, G.B., et al., The partitioning of $\mathrm{NO}_{\mathrm{y}}$ species in the summer Arctic stratosphere, Geophys. Res. Lett.,26,1157-1160, 1999.

Ravishankara, A.R., et al., Photochemistry of ozone: Surprises and recent lessons, Science, 280, 60-61, 1998.

Salawitch, R.J., et al., The diurnal variation of hydrogen, nitrogen, and chlorine radicals: Implications for the heterogeneous production of $\mathrm{HNO}_{2}$, Geophys. Res. Lett., 21, 2551-2554, 1994.

Singer, R.J., et al., Measurement of the absorption cross-section of peroxynitric acid between 210 and $330 \mathrm{~nm}$ in the range 253-298 K, J. Photochem. Photobiol. A, 48, 17-32, 1989.

Toumi, R., A potential new source of $\mathrm{OH}$ and odd-nitrogen in the atmosphere, Geophys. Res. Lett., 20, 25-28, 1993.

Zabel, F., Unimolecular decomposition of peroxynitrates, Zeitschrift fur Physikalische Chemie, 188, 119-142, 1995.

Zhang, R., M.T. Leu, L.F. Keyser, Heterogeneous chemistry of $\mathrm{HO}_{2} \mathrm{NO}_{2}$ in $\mathrm{H}_{2} \mathrm{SO}_{4}(l)$, J. Phys. Chem. A, 101, 3324-3330, 1997.

P. Wennberg, MS 150-21, Caltech, 1200 E. California Blvd., Pasadena, CA 91125, (wennberg@gps.caltech.edu).

R. Salawitch, JPL, 4800 Oak Grove Dr., Pasadena, CA 91109.

T. Hanisco, E. Lanzendorf, E. Hintsa, K. Perkins, Department of Chemistry, Harvard, 12 Oxford St., Cambridge, MA 02138.

D. Donaldson, Department of Chemistry, University of Toronto, Toronto, Ontario, Canada M5S $1 \mathrm{A1}$.

V. Vaida, Department of Chemistry, Univ. of Colorado, Boulder, $\mathrm{CO}, 80309$.

S. Lloyd, W. Swartz, T. Kusterer, D. Anderson, APL, The Johns

Hopkins University, Johns Hopkins Road, Laurel, Maryland 20723. R.S. Gao, NOAA Aeronomy Laboratory, Boulder, CO, 80307.

R. Cohen, University of California, Berkeley, CA 94720.

(Received December 21, 1998; revised March 12; accepted March 24, 1999.) 